\title{
First report of Pseudocercospora jahnii in the Philippines
}

\author{
B. D. Acabal Jr. • J. Z. Groenewald • P. W. Crous • \\ C. J. R. Cumagun
}

Received: 18 November 2013 / Accepted: 15 October 2014 / Published online: 21 October 2014

(C) Australasian Plant Pathology Society Inc. 2014

\begin{abstract}
Young and mature leaves with necrotic spots of Tabebuia pallida were collected in field experimental plots in Mandaue City, Cebu, and Laguna in the Philippines. The leaf spots were colonised by a cercosporoid fungus identified as Pseudocercospora jahnii, which is a first report of this pathogen from the Philippines.
\end{abstract}

\section{Keywords Pseudocercospora jahnni · Tabebuia pallida}

Tabebuia (Trumpet creepers; Bignoniaceae) is a genus of tropical trees with a worldwide distribution, mostly cultivated as flowering trees (Fischer et al. 2004). Species of Tabebuia originate from Cuba and Hispaniola, and are native to the American subtropics from Mexico to Argentina (Grose and Olmstead 2007). In November 2012, a survey of diseases of Tabebuia pallida was conducted in the provinces of Cebu and Laguna of the Philippines, and a characteristic black leaf spot disease associated with a Pseudocercospora sp. detected. Based on the characteristic disease symptomatology and morphology of the fungus, the causal organism was identified as Pseudocercospora jahnii (Crous and Braun 2003), which was also recently reported from Thailand (Phengsintham et al. 2013).

\section{B. D. Acabal Jr.}

Regional Crop Protection Center, Department of Agriculture-Field Research Unit, DA-MES Complex, Maguikay, Mandaue City, Cebu, Philippines

J. Z. Groenewald • P. W. Crous

CBS-KNAW Fungal Biodiversity Centre, Uppsalalaan 8, 3584

CT Utrecht, The Netherlands

B. D. Acabal Jr. C. J. R. Cumagun $(\bowtie)$

Crop Protection Cluster, College of Agriculture, University of the Philippines Los Baños, College, Laguna 4031, Philippines

e-mail: christian_cumagun@yahoo.com
Leaf spots were black, amphigenous, circular to angular, up to $20 \mathrm{~mm}$ in diameter, with yellow margins (Fig. 1a), becoming necrotic and grey-brown with age. Lesions were covered with black conidial masses, which tended to be more pronounced on the lower leaf surfaces. Leaf spots coalesced with age, leading to premature leaf shedding. Conidiophores arose from a well-developed brown stroma up to $40 \mu \mathrm{m}$ in diameter, were medium brown, smooth, 1-3-septate, rarely branched, $10-35 \times 3-5 \mu \mathrm{m}$, and aggregated in short, dense brown fascicles (Fig. 1b). Conidiogenous cells were medium brown, smooth, 5-15 $\times 2-4 \mu \mathrm{m}$, and proliferated sympodially. Conidia were scolecosporous, obclavate, pale brown, $(30-) 50-75(-80) \times(2.5-) 3-3.5(-4) \mu \mathrm{m}, 4-6$-septate (Fig. 1c), with unthickened, non-darkened hila.

Pseudocercospora jahnii was originally described from Tabebuia rosea collected in Venezuela (lectotype BPI 437408, designated in Braun and Urtiaga, 2012). Although conidia of the type specimen are larger than that reported from Asian collections, examination of numerous specimens from Asia and South America have shown this to be a morphologically variable taxon (U. Braun, pers. comm.), which suggests that until fresh material is collected from Venezuela, the matter of cryptic speciation within the morphospecies $P$. jahnii cannot be resolved.

Specimens were deposited in the Mycological Herbarium at the University of the Philippines Los Baños (UPLB) (CALP 12001). To confirm the identity of the causal organism, a specimen was sent to the CBS-KNAW Fungal Biodiversity Centre, Utrecht, the Netherlands (CBS), for morphological and molecular confirmation (specimen CBS H-21962, culture CPC 24235=CBS 138757). Partial translation elongation factor 1-alpha (TEF) and ITS nrDNA sequences (GenBank accession KM393284 and KM393283, respectively) were determined for the strain as explained by Hunter et al. (2006). A megablast search of the NCBI's GenBank nucleotide database using the ITS sequence derived from this culture revealed that 

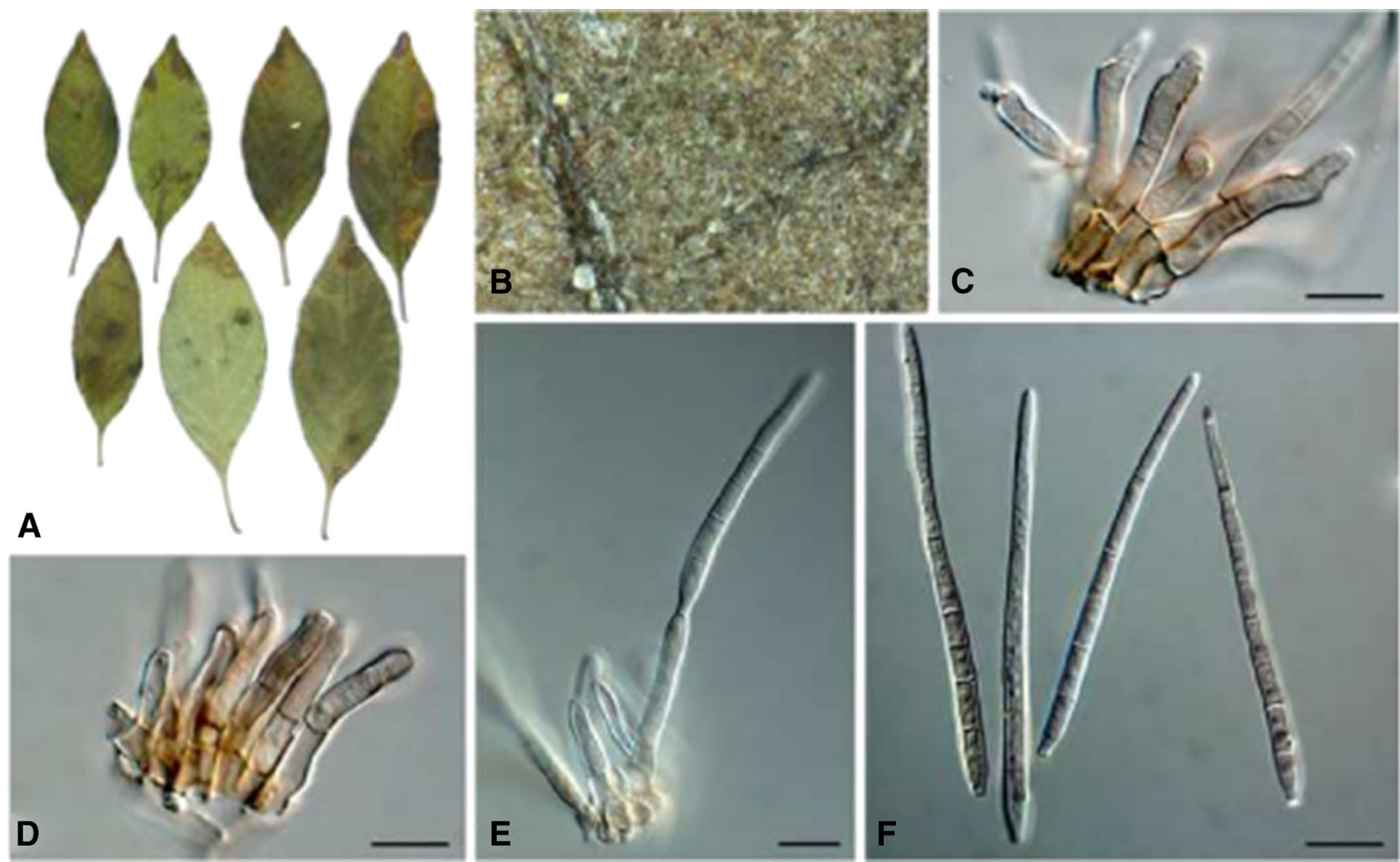

Fig 1 a. Leaf spots of Tabebuia pallida $\mathbf{b}$. Close-up of lower leaf surface, showing sporulation. c-e. Conidiophores giving rise to conidia. e. Conidia. Scale bars $=10 \mu \mathrm{m}$

it was identical to the ITS sequences of several Pseudocercospora spp (e.g. Ps. contraria GenBank GU269677, Ps. glauca GenBank GU269715, and Ps. indonesiana GenBank GU269735), and that it differed with one substitution from a single ITS sequence of Ps. jahnii present on GenBank (accession KC677903). A megablast search of the NCBI's GenBank nucleotide database using the TEF sequence derived from this culture revealed that it was not closest to Ps. basiramifera (GenBank DQ211677.2; $463 / 508$ (91\%) identical). Unfortunately, in addition to ITS, only a partial $28 \mathrm{~S}$ nrDNA sequence of PS. jahnii is available on GenBank (accession KC677933) and no protein coding loci for further comparison. This is the first record of Pseudocercospora jahnii from the Philippines.

Acknowledgments The authors would like to thank the support and funding by the Ministry of Agriculture, Forestry and Fisheries of Japan under the Programme on "On the Job Research Capacity Building for Sustainable Agriculture in Developing Countries." Identification of the host species of Tabebuia by Dr. William SM. Gruezo, Plant Biology
Division, Institute of Biological Sciences, UPLB is gratefully acknowledged.

\section{References}

Braun U, Urtiaga R (2012) New species and new records of cercosporoid hyphomycetes from Cuba and Venezuela (Part 2). Mycosphere 3: 301-329

Crous PW, Braun U (2003) Mycosphaerella and its anamorphs: 1. Names published in Cercospora and Passalora. CBS Biodiversity Series 1:1-569

Fischer E, Theisen I, Lohmann LG (2004) Bignoniaceae. In: Kaderit JW (ed) The families and genera of vascular plants, vol 7, Lamiales (except Acanthaceae including Avicenniaceae). Springer, Berlin, pp 9-38

Grose SO, Olmstead RG (2007) Evolution of a charismatic neotropical clade: molecular phylogeny of Tabebuia s.1., crescentieae, and allied genera (Bignoniaceae). Syst Bot 32:650-659

Hunter GC, Wingfield BD, Crous PW, Wingfield MJ (2006) A multigene phylogeny for species of Mycosphaerella occurring on Eucalyptus leaves. Stud Mycol 55:147-161

Phengsintham P, Braun U, McKenzie EHC, Chukeatirote E, Cai L, Hyde KD (2013) Monograph of Cercosporoid fungi from Thailand. Plant Pathol Quar 3:67-138 